\title{
Intraoperative hypotension is associated with shortened overall survival after lung cancer surgery
}

Wen-Wen Huang ${ }^{1}$, Wen-Zhi Zhu' ${ }^{2}$, Dong-Liang Mu${ }^{1}$, Xin-Qiang $\mathrm{Ji}^{3}$, Xue-Ying Li ${ }^{4}$, Daqing $\mathrm{Ma}^{5}$ and Dong-Xin Wang ${ }^{1,6^{*}}$ (i)

\begin{abstract}
Background: Intraoperative hypotension is associated with increased morbidity and mortality after surgery. We hypothesized that intraoperative hypotension might also be associated with worse long-term survival after cancer surgery. Herein, we analyzed the correlation between intraoperative hyper-/hypotension and overall survival after lung cancer surgery.

Methods: In this retrospective cohort study, 676 patients who received lung cancer surgery between January 1, 2006 and December 31, 2009 were reviewed. Intraoperative hyper- and hypotension were defined according to their correlation with long-term survival. The primary endpoint was overall survival. The association between episodes of intraoperative hyper-/hypotension and overall survival was analyzed with multivariable Cox proportional hazard models.

Results: Long-term follow-ups were completed in 515 patients with a median duration of 5.2 years. The estimated 5-year survival rates were $66.5,61.3,56.5$, and $41.2 \%$ in patients with only hypertension (systolic blood pressure > $140 \mathrm{mmHg}$ for $\geq 5 \mathrm{~min}$ ), with both hyper- and hypotension (systolic blood pressure $<100 \mathrm{mmHg}$ for $\geq 5 \mathrm{~min}$ ), with neither hyper- nor hypotension, and with only hypotension during surgery, respectively. After adjusting confounding factors, intraoperative hypotension was significantly associated with shortened overall survival (compared with patients with only intraoperative hypertension, those with both hyper- and hypotension: hazard ratio [HR]1.033, 95\% confidence interval [Cl] 0.709 to 1.507, $p=0.864$; those with neither hyper- nor hypotension: HR $0.952,95 \% \mathrm{Cl} 0.608$ to $1.489, p=0.829$; those with only hypotension: HR $1.736,95 \% \mathrm{Cl} 1.218$ to $2.475, p=0.002$ ).
\end{abstract}

Conclusions: For patients undergoing lung cancer surgery, intraoperative hypotension, but not hypertension, was associated with shortened overall survival.

Keywords: Lung neoplasms, Thoracic surgical procedures, Hypotension, Prognosis

\footnotetext{
*Correspondence: wangdongxin@hotmail.com; dxwang65@bjmu.edu.cn

'Department of Anesthesiology and Critical Care Medicine, Peking University First Hospital, Beijing 100034, China

${ }^{6}$ Department of Outcomes Research Consortium, Cleveland Clinic, Cleveland, $\mathrm{OH}, \mathrm{USA}$

Full list of author information is available at the end of the article
}

(c) The Author(s). 2020 Open Access This article is licensed under a Creative Commons Attribution 4.0 International License, which permits use, sharing, adaptation, distribution and reproduction in any medium or format, as long as you give appropriate credit to the original author(s) and the source, provide a link to the Creative Commons licence, and indicate if changes were made. The images or other third party material in this article are included in the article's Creative Commons licence, unless indicated otherwise in a credit line to the material. If material is not included in the article's Creative Commons licence and your intended use is not permitted by statutory regulation or exceeds the permitted use, you will need to obtain permission directly from the copyright holder. To view a copy of this licence, visit http://creativecommons.org/licenses/by/4.0/ The Creative Commons Public Domain Dedication waiver (http://creativecommons.org/publicdomain/zero/1.0/) applies to the data made available in this article, unless otherwise stated in a credit line to the data. 


\section{Background}

Lung cancer accounts for $13 \%$ of the total cancer diagnosis and is the primary cause of cancer deaths in males and the second cause of cancer death in females globally [1]. It has the highest incidence and mortality among all malignant tumors in China [2]. Timely surgery is the front-line therapy for lung cancer and hence, continuous efforts have been made to evolve surgical strategies and techniques [3, 4]. However, perioperative period is characterized with profound changes in immune function which are attributed by anesthesia- and surgery-related factors including volatile anesthetics and opioids, surgical trauma, bleeding and blood transfusion, hypothermia, neuroendocrine stress response, and inflammation. It has been suggested that anesthetic management may also affect long-term outcome of patients after cancer surgery [5-7].

Indeed, even when well-controlled, hypo- and hypertensive episodes are common during anesthesia and surgery; and poor management of intraoperative blood pressure was associated with the occurrence of perioperative cardiovascular events, organ injury and mortality [8-10] and even 1-year mortality [11]. In a cohort study of patients undergoing surgery for colorectal liver metastases, high number of intraoperative hypotensive episodes was associated with shortened recurrence-free survival [12]. On the other hand, it was reported that long-term survival was compromised by perioperative hypertension in renal or rectal cancer patients $[13,14]$. We hypothesized that intraoperative hypo-/hypertension might also affect long-term survival after lung cancer surgery. However, evidences are lacking on this topic. This study aimed to analyze the possible association between intraoperative hyper-/hypotensive episodes and overall survival in patients after surgery for lung cancer.

\section{Methods}

This retrospective cohort study was a further analysis of our patients' data [15]. The study protocol received ethics approval from the Clinical Research Ethics Committee of Beijing University Cancer Hospital (2014[074]). Written informed consents from patients were waived by the Ethics Committee because the nature of study was pure observational, and no intervention was given to any patients; but all enrolled patients verbally agreed to participate in long-term follow-up. All the collected data were protected, and patient's confidentiality was guaranteed.

\section{Patients}

Consecutive patients who received intrathoracic lung surgery between January 1, 2006 and December 31, 2009 in Peking University Cancer Hospital were screened. The inclusion criteria included: (1) age $\geq 18$ years, (2) lung cancer diagnosis was confirmed by pathological examination after surgery, and (3) the data of intraoperative blood pressure could be tracked in the electronic anesthesia record system. Patients who met any of the following criteria were excluded: (1) existence of primary cancer in other place, (2) metastatic or recurrent lung cancer, (3) lost to follow-up, and (4) manually recorded intraoperative monitoring data or missing data.

\section{Collection of baseline and perioperative data}

Data collection was performed by qualified researchers from inpatient medical record system. Baseline data included age, sex, body mass index (BMI), smoking history, preoperative comorbidity, previous history of chemotherapy for cancer, and American Society of Anesthesiologists (ASA) physical status classification. Intraoperative data included methods of anesthesia, types and doses of anesthetics, estimated blood loss, infusion of blood products, uses and doses of glucocorticoids, uses and doses of nonsteroidal anti-inflammatory drugs, type and duration of surgery, and performance of mediastinal lymph node dissection. Postoperative data included pathological diagnosis, maximal tumor size, grade of tumor cell differentiation, pathological Tumor-NodeMetastasis (TNM) stage [16], and occurrence of complications during hospital stay after surgery.

\section{Data acquisition for intraoperative blood pressure}

The readings of intraoperative blood pressure, which were stored in the electronic anesthesia record system and were recorded at least every 5 min during operation, were obtained from each patient's electronic anesthesia chart. Blood pressure was monitored via a standard automatic arm cuff or through an intra-arterial catheter. When both non-invasive and invasive measurements were performed, invasive blood pressure was adopted for analysis. The last systolic blood pressure (SBP) reading before anesthesia induction was recorded as preanesthesia SBP. The time of anesthesia induction was defined as the moment of anesthetic administration or $3 \mathrm{~min}$ before the first reading of expired carbon dioxide, whichever came first [17].

Intraoperative hyper- and/or hypotension were defined according to the absolute thresholds and durations of SBP. We adopt this criterion because it is commonly used in daily practice than either relative thresholds (such as percent change from baseline) or mean blood pressure, and SBP is the primary target of intervention [18]. The criteria of intraoperative hypertension (SBP > 140 or $160 \mathrm{mmHg}$, for a minimal duration of 5 or 10 min) and hypotension (SBP $<100$ or $90 \mathrm{mmHg}$, for a minimal duration of 5 or $10 \mathrm{~min}$ ) were chosen based on the literature $[9,11,19]$. 


\section{Postoperative follow-up}

Postoperative follow-up was performed with outpatient interview, telephone interview or letter communication. Patients were followed-up at 6 and 12 months during the first year after surgery, and then once a year thereafter. Data of postoperative treatment including chemoand/or radiotherapy were collected. The status of survival was confirmed during each follow-up, and the date and causes of death (if occurred) were recorded according to the medical certificate of death. Follow-up was continued until the patient died or was lost to follow-up. For all cases, follow-up was conducted by trained staff from the Department of Medical Records and Statistics of Peking University Cancer Hospital. The primary endpoint was overall survival, i.e., the duration from surgery to death of any cause.

\section{Statistical analysis}

Continuous data with non-normal distribution were reported as median (interquartile range [IQR]). Categorical data were reported as numbers (\%). The association between baseline/perioperative variables and long-term overall survival were analyzed with univariate Cox proportional hazards regression analyses based on clinical importance and the literature $[15,20-23]$. The criteria of absolute thresholds and episode durations for the diagnosis of intraoperative hypo-/hypertension were decided according to the hazard ratios estimated with Cox proportional hazard regression models with or without adjustment for confounding factors (set as $\mathrm{p}<0.20$ in univariable analyses or were considered as clinically important). Postoperative survival estimation was made by Kaplan-Meier survival analysis for patients with four combinations of intraoperative hypertension (yes, no) and intraoperative hypotension (yes, no). The association between different combinations of intraoperative hyper -/hypotension and overall survival were analyzed with Cox proportional hazard regression models and adjusted for confounding factors. Missing data were not replaced. All tests were two-sided. A two-sided $\mathrm{p}<0.05$ was considered to be statistically significant. Bonferroni correction was performed for multiple comparisons. The statistical software package SPSS version 25.0 (IBM SPSS Inc., Chicago, IL, USA) was used for all analyses.

Sample-size calculation was not performed beforehand. However, considering the high number of events (nearly 270 deaths) compared with the number of variables (18 variables) included in the Cox model, the "ten events per variable" rule was exceeded, indicating sufficient accuracy of the regression estimates [24].

\section{Results}

Patient recruitment and follow-up results

Six hundred seventy-six patients underwent lung cancer surgery from January 1, 2006 to December 31, 2009. Of these, 561 met the eligibility criteria, 515 completed the long-term follow-ups and were included for the final analysis (Fig. 1). The last follow-up was performed on December 31, 2015. The median follow-up interval was 5.2 years (IQR 2.0-6.6). At the end of the long-term follow-up, 263 patients $(51.1 \%)$ died and among them, 249 (94.7\%) died of cancer. The median duration of

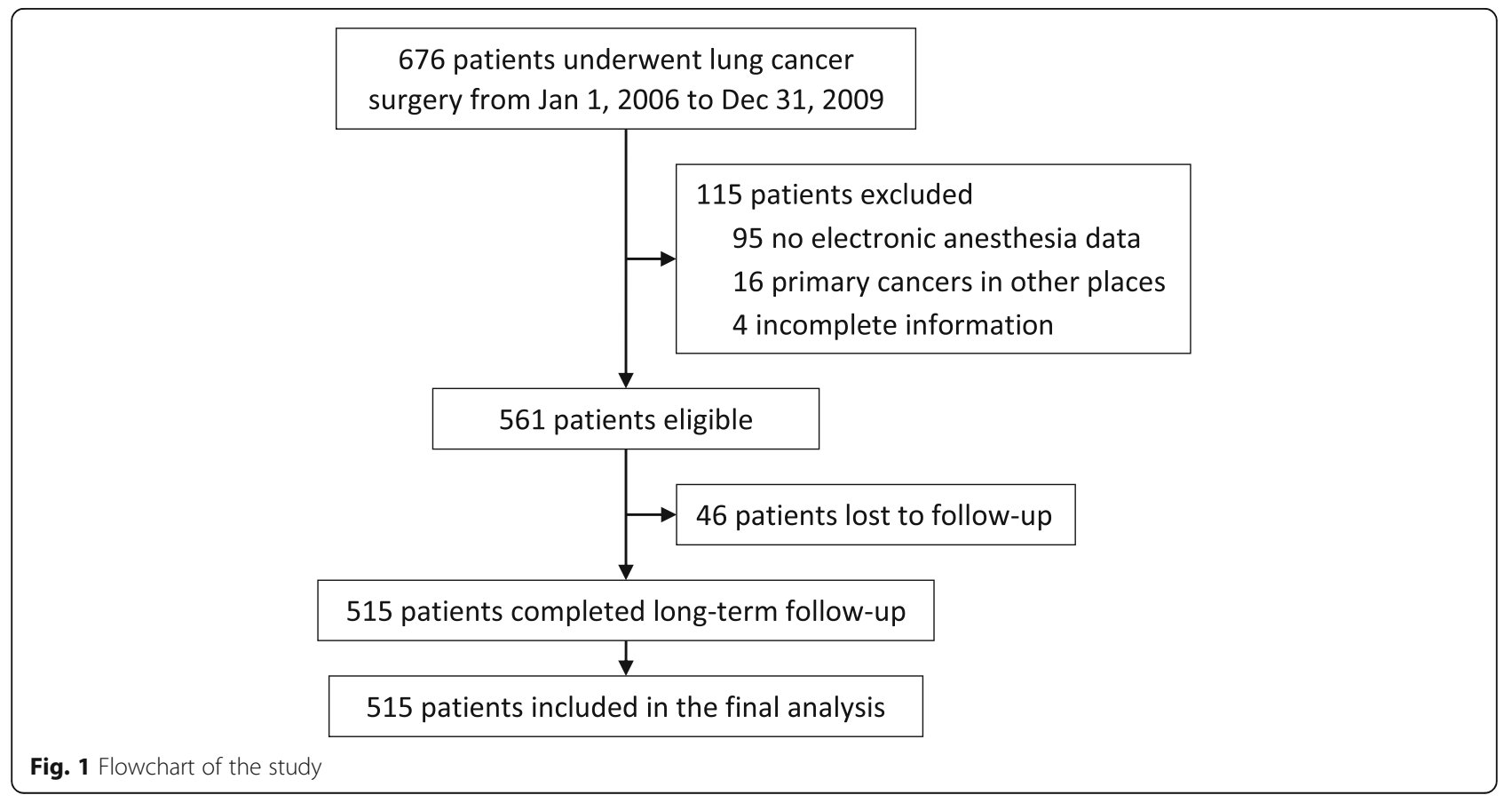


overall survival was 63.2 months (IQR 28.1-79.5) (See Additional files 1 and 2).

\section{Potential confounding factors of overall survival}

Eighteen factors were identified by univariable analyses $(p<0.20)$ or considered clinically important, including age, body mass index, male sex, chronic smoking, history of hypertension, preoperative chemotherapy, perioperative sufentanil equivalent, perioperative dexamethasone, perioperative flurbiprofen axetil, intraoperative blood transfusion, conservative resection/biopsy (vs. other types of surgery), mediastinal lymph node dissection, histological type as small-cell lung cancer, maximal tumor size, tumor differentiation, pathological Tumor-Node-Metastasis (TNM) stage, occurrence of postoperative complications, and postoperative chemo-/radiotherapy (Table 1). Of these, maximal tumor size was excluded from further multivariate analysis because it was closely related to pathological TNM stage.

\section{Criteria of intraoperative hypo- and hypertension}

Potential criteria included four thresholds of SBP (higher than 140 or $160 \mathrm{mmHg}$, and lower than 100 or 90 $\mathrm{mmHg}$ ) with two minimal length of durations (5 or 10 $\mathrm{min}$ ). Results of Cox proportional hazard regression analyses (Table 2) showed that intraoperative hypertension, defined as SBP $>140 \mathrm{mmHg}$ for at least $5 \mathrm{~min}$, was associated with prolonged overall survival (adjusted hazard ratio [HR] $0.719,95 \%$ confidence interval [CI] 0.545 to $0.948, p=0.019)$; whereas intraoperative hypotension, defined as $\mathrm{SBP}<100 \mathrm{mmHg}$ for at least $5 \mathrm{~min}$, was associated with shortened overall survival (adjusted HR $1.382,95 \%$ CI 1.047 to $1.825, p=0.023)$. Therefore, $\mathrm{SBP}>140 \mathrm{mmHg}$ for at least $5 \mathrm{~min}$ was adopted as the criterion of intraoperative hypertension, and SBP $<100$ $\mathrm{mmHg}$ for at least $5 \mathrm{~min}$ was adopted as the criterion of intraoperative hypotension in the subsequent analyses.

\section{Intraoperative blood pressure events and long-term survival}

The estimated 5-year survival rates were 66.5, 61.3, 56.5, and $41.2 \%$ in patients with only hypertension, with both hyper- and hypotension, with neither hyper- nor hypotension, and with only hypotension during surgery, respectively (Table 3 ). Patients who experienced only hypotension during surgery had a significantly shortened overall survival when compared with those who experienced only hypertension $(p<0.001)$ and those who experienced both hyper- and hypotension $(p=0.008)$ during surgery (adjusted significance criterion after Bonferroni correction was $p<0.0167$ ) (Fig. 2). After adjusting potential confounding factors, patients who experienced only intraoperative hypotension had a significantly shortened overall survival when compared with those who experienced only intraoperative hypertension (adjusted HR 1.736, 95\% CI 1.218 to $2.475, p=0.002$ ) (Table 4).

\section{Discussion}

In this retrospective cohort study, 515 patients were followed up for a median of 5.2 years after lung cancer surgery. Intraoperative hypertension (SBP $>140 \mathrm{mmHg}$ for at least $5 \mathrm{~min}$ ) and hypotension $(\mathrm{SBP}<100 \mathrm{mmHg}$ for at least $5 \mathrm{~min}$ ) were defined according to their association with overall survival. When compared with patients who experienced only intraoperative hypertension, those who experienced only intraoperative hypotension had significantly shortened overall survival after correction for confounding factors.

The definition of intraoperative hyper-/hypotension varied widely in the literature. It is generally accepted that $\mathrm{SBP}>160 \mathrm{mmHg}$ during surgery is defined as intraoperative hypertension, and $\mathrm{SBP}<80 \mathrm{mmHg}$ as hypotension $[9,17]$. In a recent consensus statement, it is suggested that brief durations of $\mathrm{SBP}<100 \mathrm{mmHg}$ are harmful during noncardiac surgery [25]. However, these definitions are usually introduced according to their effects on perioperative "short-term" outcomes. In the present study, we defined intraoperative hyper -/hypotension according to their effects on long-term survival. As such, we adopted an episode of SBP $>140$ $\mathrm{mmHg}$ for at least $5 \mathrm{~min}$ as intraoperative hypertension and an episode of SBP $<100 \mathrm{mmHg}$ for at least $5 \mathrm{~min}$ as hypotension.

Perioperative hypertension is associated with an increased risk of adverse events, including cardiovascular morbidity or even death [26, 27]. Regarding long-term outcome, it was reported that pre- and postoperative hypertension negatively affects longterm survival in patients after renal or rectal cancer surgery $[13,14]$. However, the opposite effects of intraoperative hypertension were also reported. For example, Monk and co-workers [9] reported that intraoperative hypertension did not affect 30-day mortality; and in the study of Levin and colleagues [28] , 30-day survival was higher in hypertensive patients not taking antihypertensive medication. In the present study, patients with intraoperative hypertension had higher overall survival when compared with those without. It should be noted that our threshold of intraoperative hypertension is much lower than in many other studies $[9,13,26]$ and is actually the upper normal limit. Considering that about one fourth of our patients had preoperative hypertension and more than half of our patients had "baseline" SBP of higher than $140 \mathrm{mmHg}$, an intraoperative SBP of $140 \mathrm{mmHg}$ meant that it was closer to baseline level. This 
Table 1 Baseline and perioperative variables and their univariate association with overall survival

\begin{tabular}{|c|c|c|c|}
\hline Factors & Variables $(n=515)$ & Univariate HR $(95 \% \mathrm{CI})^{\text {a }}$ & $p$ value \\
\hline Age (yr.) & $61(53-67)$ & $1.201(0.941-1.533)$ & 0.141 \\
\hline Body mass index $\left(\mathrm{kg} \mathrm{m}^{-2}\right)$ & $24.2(22.2-26.1)$ & $0.956(0.921-0.992)$ & 0.018 \\
\hline Male sex & $328(63.7 \%)$ & $1.473(1.132-1.916)$ & 0.004 \\
\hline Chronic smoking ${ }^{b}$ & $277(53.8 \%)$ & $1.296(1.015-1.656)$ & 0.038 \\
\hline \multicolumn{4}{|l|}{ Preoperative comorbidity } \\
\hline Coronary heart disease & $30(5.8 \%)$ & $0.868(0.507-1.487)$ & 0.606 \\
\hline Hypertension & 135 (26.2\%) & $0.644(0.478-0.869)$ & 0.004 \\
\hline Diabetes mellitus & $56(10.9 \%)$ & $0.889(0.597-1.324)$ & 0.563 \\
\hline Stroke & $17(3.3 \%)$ & $1.417(0.775-2.592)$ & 0.258 \\
\hline Preoperative chemotherapy ${ }^{c}$ & $57(11.1 \%)$ & $1.608(1.136-2.278)$ & 0.007 \\
\hline Charlson Comorbidity Index ${ }^{d}$ & $0(0-0)$ & $1.010(0.798-1.279)$ & 0.934 \\
\hline \multicolumn{4}{|l|}{ ASA classification } \\
\hline I & $183(35.5 \%)$ & 1.000 & \\
\hline$\|+\|$ & $332(64.5 \%)$ & $0.851(0.663-1.093)$ & 0.205 \\
\hline \multicolumn{4}{|l|}{ Pre-anesthesia SBP $(\mathrm{mmHg})^{e}$} \\
\hline$<120$ & $85(16.5 \%)$ & 1.000 & \\
\hline $120-139$ & $153(29.7 \%)$ & $1.093(0.758-1.576)$ & 0.633 \\
\hline $140-159$ & $158(30.7 \%)$ & $0.808(0.556-1.175)$ & 0.264 \\
\hline$\geq 160$ & $119(23.1 \%)$ & $1.015(0.690-1.492)$ & 0.940 \\
\hline Combined epidural-general anesthesia (vs. general anesthesia) & $110(21.4 \%)$ & $0.948(0.707-1.272)$ & 0.723 \\
\hline \multicolumn{4}{|l|}{ Use of general anesthetics } \\
\hline Propofol (vs. no use) & $459(89.1 \%)$ & $1.207(0.799-1.823)$ & 0.372 \\
\hline Etomidate (vs. no use) & $118(22.9 \%)$ & $0.944(0.814-1.094)$ & 0.446 \\
\hline Nitrous oxide (vs. no use) & $94(18.3 \%)$ & $0.951(0.820-1.102)$ & 0.504 \\
\hline Sevoflurane (vs. no use) & $198(38.4 \%)$ & $0.944(0.739-1.207)$ & 0.647 \\
\hline Isoflurane (vs. no use) & $310(60.2 \%)$ & $1.067(0.835-1.365)$ & 0.603 \\
\hline Perioperative sufentanil equivalent $(\mu \mathrm{g})$ & $280(93-320)$ & $0.999(0.998-1.000)$ & 0.033 \\
\hline Perioperative use of dexamethasone & $266(51.7 \%)$ & $0.776(0.608-0.989)$ & 0.041 \\
\hline Perioperative use of flurbiprofen axetil & $311(60.4 \%)$ & $0.761(0.596-0.971)$ & 0.028 \\
\hline Intraoperative crystalloid (ml) & $1350(1100-1600)$ & $1.000(1.000-1.000)$ & 0.434 \\
\hline Intraoperative artificial colloid (ml) & $500(500-1000)$ & $1.000(1.000-1.000)$ & 0.538 \\
\hline Intraoperative vasoactive drugs & $101(19.6 \%)$ & $1.067(0.793-1.437)$ & 0.668 \\
\hline Intraoperative blood transfusion & $9(1.7 \%)$ & $3.018(1.490-6.109)$ & 0.002 \\
\hline Duration of surgery (hr.) & $4.0(3.0-4.0)$ & $0.952(0.853-1.064)$ & 0.386 \\
\hline Conservative resection or biopsy (vs. other types of surgery) ${ }^{f}$ & $45(8.9 \%)$ & $2.995(2.112-4.247)$ & $<0.001$ \\
\hline Mediastinal lymph node dissection & $461(89.5 \%)$ & $0.429(0.307-0.599)$ & $<0.001$ \\
\hline Histological type as small-cell lung cancer & $16(3.1 \%)$ & $2.584(1.477-4.521)$ & 0.001 \\
\hline Maximal tumor size $(\mathrm{cm})$ & $3.0(2.0-4.0)$ & $1.175(1.106-1.249)$ & $<0.001$ \\
\hline \multicolumn{4}{|l|}{ Tumor differentiation } \\
\hline Highly differentiated & $62(11.0 \%)$ & 1.000 & \\
\hline Moderately differentiated & $315(61.2 \%)$ & $2.047(1.257-3.332)$ & 0.004 \\
\hline Poorly differentiated & $60(11.7 \%)$ & $3.671(2.116-6.369)$ & $<0.001$ \\
\hline Undifferentiated & $78(15.1 \%)$ & $2.420(1.390-4.214)$ & 0.002 \\
\hline
\end{tabular}

Pathological TNM stage ${ }^{g}$ 
Table 1 Baseline and perioperative variables and their univariate association with overall survival (Continued)

\begin{tabular}{|c|c|c|c|}
\hline Factors & Variables $(n=515)$ & Univariate $\mathrm{HR}(95 \% \mathrm{Cl})^{a}$ & $p$ value \\
\hline I & $201(41.5 \%)$ & 1.000 & \\
\hline$\|$ & $100(20.7 \%)$ & $2.762(1.879-4.060)$ & $<0.001$ \\
\hline III & $140(28.9 \%)$ & $4.388(3.118-6.176)$ & $<0.001$ \\
\hline IV & $43(8.9 \%)$ & $6.781(4.398-10.457)$ & $<0.001$ \\
\hline Occurrence of postoperative complications ${ }^{h}$ & $370(71.8 \%)$ & $1.387(1.043-1.845)$ & 0.024 \\
\hline Postoperative chemo-/radiotherapy & $283(55.0 \%)$ & $1.531(1.198-1.957)$ & 0.001 \\
\hline
\end{tabular}

Data are median (interquartile range) or number (\%)

Abbreviations: HR hazard ratio, Cl confidence interval, ASA American Society of Anesthesiologists, SBP systolic blood pressure, NSAIDs non-steroidal anti-

inflammatory drugs, TNM stage Tumor-Node-Metastasis stage

a Performed with COX proportional-hazards regression analyses

b Smoking of half a pack of cigarettes per day for at least 2 years, either former or current smoker

c Missing data in 1 patient

${ }^{d}$ According to the 1987 version without age correction

e Defined as the last systolic blood pressure reading in the operating room before anesthesia induction

${ }^{f}$ Performed in patients with nonresectable cancer; compared with lobectomy, pneumonectomy, wedge resection, and bronchial resection. Missing data in

7 patients

${ }^{9}$ According to the 7th edition of the American Joint Committee on Cancer staging system. Missing data in 31 patients

${ }^{\mathrm{h}}$ Defined as newly occurred medical conditions that required therapeutic intervention during hospital stay after surgery (see supplement Table 2)

partially explains why our results showed favorable effects of intraoperative hypertension [29].

Importantly, the harmful effects of intraoperative hypotension have often been reported including that a previous elegant study reported "triple low" profoundly affected perioperative outcome [30]. Indeed, intraoperative hypotension is associated with an increased risk of myocardial injury, acute kidney injury, and even 30-day mortality $[8,9,28,31]$. Furthermore, it seems that these harmful effects last long time after surgery. For example, Bijker and co-workers [11] reported that intraoperative hypotension was a predictor of 1-year mortality in the elderly after noncardiac surgery. In the study reported by Younes, Rogatko and Brennan [12], intraoperative hypotension episodes were associated with early recurrence in patients after surgery for liver metastases from colorectal origin. In line with the above findings, our results showed that, in patients undergoing lung cancer surgery, even a short duration of mild intraoperative hypotension might worsen long-term survival (Fig. 2, Tables 3 and 4).

The underlying mechanisms for how intraoperative hypotension impact long-term survival remain unclear but may include the following. First, intraoperative hypotension increases the risk of perioperative vital organ injury including myocardial injury and acute kidney injury $[8,31]$, each of which is associated with worsened overall survival $[32,33]$. However, this was not the case in our patients as $94.7 \%(249 / 263)$ of patient deaths were caused by cancer. Second, microenvironmental hypoxia, which is a common feature in solid cancer [34], might have been aggravated by intraoperative hypotension and thus promoted cancer aggressiveness and metastasis via hypoxia inducible factor mechanisms $[35,36]$. Third, hypoxia resulting from intraoperative hypotension might have augmented systematic inflammation [37] which enhances cancer recurrence and cancer-related death [38]. Interestingly, a recent study showed that individualized intraoperative blood pressure management reduced systemic inflammatory response syndrome and organ dysfunction after surgery [29] although its long-term impact on surgical outcome has not been reported yet.

The main strength of this study was the long-term follow-up which was completed by specialized personnel

Table 2 Association between different threshold and duration of intraoperative hyper-/hypotension and overall survival

\begin{tabular}{|c|c|c|c|c|c|c|}
\hline \multirow[t]{2}{*}{ Thresholds } & \multirow[t]{2}{*}{$\mathrm{N}$} & \multicolumn{2}{|l|}{ Episode duration of $\geq 5 \mathrm{~min}$} & \multirow[t]{2}{*}{$\mathrm{N}$} & \multicolumn{2}{|c|}{ Episode duration of $\geq 10 \mathrm{~min}$} \\
\hline & & Unadjusted HR $(95 \% \mathrm{Cl})^{a}$ & Adjusted HR $(95 \% \mathrm{Cl})^{a, b}$ & & Unadjusted HR $(95 \% \mathrm{Cl})^{a}$ & Adjusted HR (95\% Cl) $)^{a, b}$ \\
\hline Intraoperative SBP > $160 \mathrm{mmHg}$ & 101 & $1.132(0.841-1.532)$ & 1.371 (0.974-1.929) & 50 & $1.064(0.714-1.584)$ & $1.516(0.980-2.343)$ \\
\hline Intraoperative SBP > $140 \mathrm{mmHg}$ & 286 & $0.671(0.526-0.854)$ & $0.719(0.545-0.948)$ & 201 & $0.687(0.532-0.887)$ & $0.795(0.594-1.063)$ \\
\hline Intraoperative SBP $<100 \mathrm{mmHg}$ & 279 & $1.371(1.072-1.754)$ & $1.382(1.047-1.825)$ & 201 & $1.084(0.846-1.387)$ & $1.118(0.840-1.488)$ \\
\hline Intraoperative SBP $<90 \mathrm{mmHg}$ & 73 & $0.993(0.701-1.406)$ & $0.903(0.613-1.330)$ & 46 & $1.111(0.736-1.679)$ & $1.040(0.652-1.660)$ \\
\hline
\end{tabular}

Abbreviations: $N$ number of patients with events, $H R$ hazard ratio, $C l$ confidence interval, $S B P$ systolic blood pressure. Results in bold indicate those with $\mathrm{p}<0.05$

${ }^{a}$ Performed with COX proportional-hazards regression analyses

${ }^{\mathrm{b}}$ Adjusted for age, body mass index, male gender, chronic smoking, history of hypertension, preoperative chemotherapy, perioperative sufentanil equivalent, perioperative dexamethasone, perioperative flurbiprofen axetil, intraoperative blood transfusion, conservative resection/biopsy (vs. other types of surgery), mediastinal lymph node dissection, small cell lung cancer, tumor differentiation, pathological Tumor-Node-Metastasis stage, occurrence of postoperative complications, and postoperative chemo-/radiotherapy. Maximal tumor size was excluded due to correlation with pathological Tumor-Node-Metastasis stage 
Table 3 Estimated survival status of patients with different combinations of intraoperative hyper-/hypotension

\begin{tabular}{|c|c|c|c|c|c|}
\hline Conditions & $\mathrm{N}$ & $\begin{array}{l}\text { Mean overall survival in } \\
\text { months }(95 \% \mathrm{Cl})\end{array}$ & $\begin{array}{l}\text { 1-yr survival rate in \% } \\
(95 \% \mathrm{Cl})^{\text {a }}\end{array}$ & $\begin{array}{l}\text { 3-yr survival rate in \% } \\
(95 \% \mathrm{Cl})^{a}\end{array}$ & $\begin{array}{l}5 \text {-yr survival rate in \% } \\
(95 \% \mathrm{Cl})^{\text {a }}\end{array}$ \\
\hline $\begin{array}{l}\text { Intraoperative hypertension (+), } \\
\text { hypotension }(-)^{b}\end{array}$ & 167 & $76.9(70.6-83.2)$ & $89.8(85.3-94.3)$ & $76.6(70.1-83.1)$ & $66.5(59.2-73.8)$ \\
\hline $\begin{array}{l}\text { Intraoperative hypertension (+), } \\
\text { hypotension }(+)^{\mathrm{b}}\end{array}$ & 119 & $72.1(64.8-79.4)$ & $92.4(87.7-97.1)$ & $73.1(65.1-81.1)$ & $61.3(52.5-70.1)$ \\
\hline $\begin{array}{l}\text { Intraoperative hypertension (-), } \\
\text { hypotension }(-)^{b}\end{array}$ & 69 & $65.6(57.1-74.1)$ & $89.9(82.8-97.0)$ & $72.5(61.9-83.1)$ & $56.5(44.7-68.3)$ \\
\hline $\begin{array}{l}\text { Intraoperative hypertension (-), } \\
\text { hypotension }(+)^{b}\end{array}$ & 160 & $58.3(51.9-64.7)$ & $85.6(80.1-91.1)$ & $55.6(48.0-63.2)$ & $41.2(33.6-48.8)$ \\
\hline
\end{tabular}

Data are mean duration of overall survival in months or survival rate in $\%(95 \% \mathrm{Cl})$

Abbreviations: $\mathrm{N}$ number of patients with events, $\mathrm{Cl}$ confidence interval

a Estimated with Kaplan-Meier analyses

b Intraoperative hypertension was defined as a systolic blood pressure $>140 \mathrm{mmHg}$ for $\geq 5 \mathrm{~min}$; intraoperative hypotension was defined as a systolic blood pressure $<100 \mathrm{mmHg}$ for $\geq 5 \mathrm{~min}$

according to a standard procedure in a sufficient size patient population. Secondly, intraoperative hypo- and hypertension were defined according to their impacts on long-term survival after adjustment for confounding factors. Finally, intraoperative hypotension or hypertension alone or both in combination were analyzed separately.

Apart from the observational single-center nature, there are still some other limitations in the present study. We adopted binary definitions of intraoperative hypo- and hypertension and did not analyze the effects of duration of hypo-/hypertension. The precise data regarding pre- and intraoperative antihypertensive therapy were not collected because of lacking information in most of patient's records; although previous studies revealed no associations between antihypertensive drugs [39], including the debatable $\beta$ blockers [40], with the risk of cancer mortality. We did not consider the influence of postoperative blood pressure as these data were not documented in the electronic medical record system; but the usual case is that blood pressure returned to baseline after awaking from anesthesia at the end of surgery. This is a further analysis of the database from a similar patient cohort, which might influence the discriminatory power for the selected outcome. Nonetheless, our results provide clues for further interventional studies.

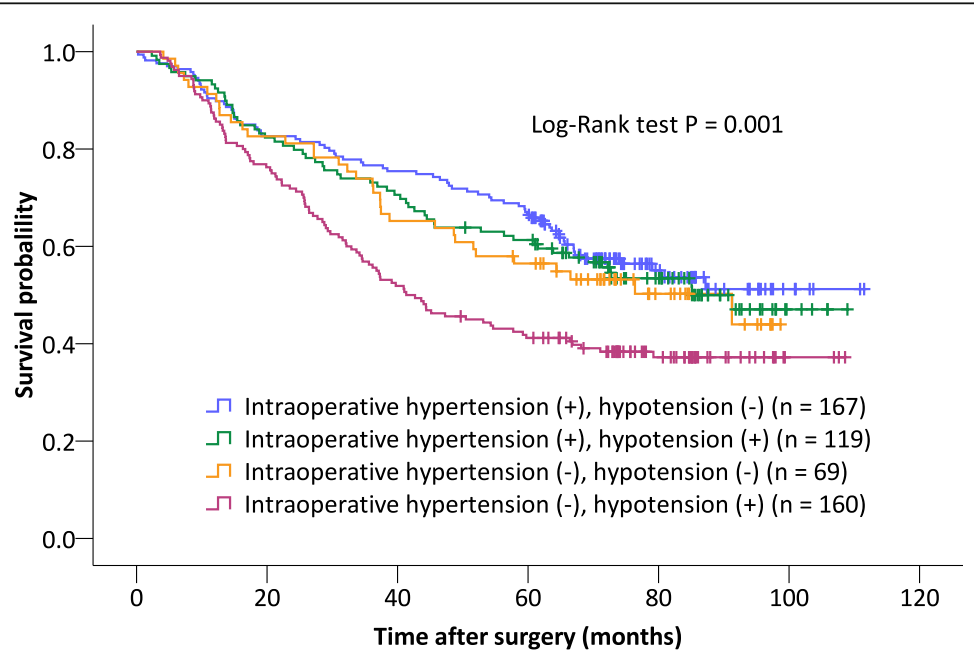

$\begin{array}{rcccccc}\begin{array}{c}\text { Number at risk } \\ \text { Only hypertension }\end{array} & 167 & 138 & 126 & 111 & 40 & 5 \\ \text { Both hyper-/hypotension } & 119 & 98 & 84 & 72 & 39 & 5 \\ \text { Neither hyper-/hypotension } & 69 & 57 & 45 & 38 & 14 & 0 \\ \text { Only hypotension } & 160 & 122 & 83 & 65 & 33 & 3\end{array}$

Fig. 2 Survival curves of patients with 4 combinations of intraoperative hyper- and hypotensive episodes. Patients who experienced only hypotension during surgery had a significantly shortened overall survival than those who experienced only hypertension $(p<0.001)$ and those who experienced both hypertension and hypotension $(p=0.008)$ (adjusted significance criterion after Bonferroni correction was $p<0.0167$ ). The cross signs indicate censored data 
Table 4 Association between different combinations of intraoperative hyper-/hypotension and duration of overall survival

\begin{tabular}{|c|c|c|c|c|c|}
\hline \multirow[t]{2}{*}{ Conditions } & \multirow[t]{2}{*}{ N } & \multicolumn{2}{|l|}{ Unadjusted $^{a}$} & \multicolumn{2}{|l|}{ Adjusted $^{a, b}$} \\
\hline & & Hazard ratio $(95 \% \mathrm{Cl})$ & $p$ value & Hazard ratio $(95 \% \mathrm{Cl})$ & $p$ value \\
\hline Intraoperative hypertension $(+)$, hypotension $(-)^{c}$ & 167 & Ref. & & Ref. & \\
\hline Intraoperative hypertension $(+)$, hypotension $(+)^{c}$ & 119 & $1.116(0.789-1.579)$ & 0.534 & $1.033(0.709-1.507)$ & 0.864 \\
\hline Intraoperative hypertension $(-)$, hypotension $(-)^{c}$ & 69 & $1.198(0.797-1.800)$ & 0.384 & $0.952(0.608-1.489)$ & 0.829 \\
\hline Intraoperative hypertension $(-)$, hypotension $(+)^{c}$ & 160 & $1.746(1.290-2.364)$ & $<0.001$ & $1.736(1.218-2.475)$ & 0.002 \\
\hline
\end{tabular}

Abbreviations: $\mathrm{N}$ number of patients with events, $\mathrm{Cl}$ confidence interval

a Performed with COX proportional-hazards regression analyses

${ }^{b}$ Adjusted for age, body mass index, male gender, chronic smoking, history of hypertension, preoperative chemotherapy, perioperative sufentanil equivalent, perioperative dexamethasone, perioperative flurbiprofen axetil, intraoperative blood transfusion, conservative resection/biopsy (vs. other types of surgery), mediastinal lymph node dissection, small cell lung cancer, tumor differentiation, pathological Tumor-Node-Metastasis stage, occurrence of postoperative complications, and postoperative chemo-/radiotherapy. Maximal tumor size was excluded due to correlation with pathological Tumor-Node-Metastasis stage c Intraoperative hypertension was defined as a systolic blood pressure $>140 \mathrm{mmHg}$ for $\geq 5 \mathrm{~min}$; intraoperative hypotension was defined as a systolic blood pressure $<100 \mathrm{mmHg}$ for $\geq 5 \mathrm{~min}$

\section{Conclusions}

Our results showed that the estimated five-year overall survival rate following lung cancer surgery was the lowest $(41.2 \%)$ in patients with only hypotension episodes during anesthesia and surgery, in comparison to those with only hypertension (66.5\%), with both hyper- and hypotension (61.3\%), and with neither hyper- nor hypotension (56.5\%). After adjustment for confounding factors, intraoperative hypotension, but not hypertension, was associated with shortened overall survival. Interventional studies are needed to clarify the impact of intraoperative blood pressure management on long-term survival in lung cancer patients undergoing surgery.

\section{Supplementary information}

Supplementary information accompanies this paper at https://doi.org/10. 1186/s12871-020-01062-2.

\section{Additional file 1 : Table S1. Baseline data and perioperative} management.

Additional file $\mathbf{2}$ : Table S2. Data of postoperative follow-up and outcomes.

\section{Abbreviations}

SBP: Systolic blood pressure; HR: Hazard ratio; Cl: Confidence interval; BMI: Body mass index; ASA: American Society of Anesthesiologists; TNM stage: Tumor-node-metastasis stage; IQR: Interquartile range; NSAIDs: Nonsteroidal anti-inflammatory drugs

\section{Acknowledgements}

The authors gratefully acknowledge the help of Prof. Yue Yang (Department of Thoracic Surgery II, Peking University Cancer Hospital, Beijing 100142, China) in collecting data.

\section{Authors' contributions}

WWH designed the study, collected, analyzed and interpreted the data, and drafted the manuscript. She is the archival author. WZZ designed the study and collected and interpreted the data. DLM conceived and designed the study. XQJ helped collect and interpret the data. XYL contributed to the statistical analysis. DM critically revised the manuscript. DXW conceived and designed the study, reviewed the original data and the results of analyses, and critically revised the manuscript. All authors have read and approved the manuscript.

\section{Funding}

This work was funded by the National Key R\&D Program of China (2018YFC2001800). The sponsor has no role in the study design and conduct; the collection, management, analysis, and interpretation of the data; or the preparation and approval of the manuscript.

\section{Availability of data and materials}

The datasets used and analyzed in the current study are available from the corresponding author upon reasonable request.

\section{Ethics approval and consent to participate}

The Clinical Research Ethics Committee of Beijing University Cancer Hospital, Beijing, China, approved of the study and written informed consent was waived (2014[074]); all enrolled patients verbally agreed to participate in long-term follow-up.

\section{Consent for publication}

Not applicable.

\section{Competing interests}

DM is a member of the editorial board of BMC Anesthesiology. Other authors declare no conflicts of interest.

\section{Author details}

${ }^{1}$ Department of Anesthesiology and Critical Care Medicine, Peking University First Hospital, Beijing 100034, China. ${ }^{2}$ Department of Anesthesiology, Peking University Cancer Hospital, Beijing 100083, China. ${ }^{3}$ Department of Medical Records and Statistics, Peking University Cancer Hospital, Beijing 100083, China. ${ }^{4}$ Department of Biostatistics, Peking University First Hospital, Beijing 100034, China. ${ }^{5}$ Section of Anaesthetics, Pain Medicine and Intensive Care, Department of Surgery and Cancer, Imperial College London, London SW10 $9 \mathrm{NH}$, UK. ${ }^{6}$ Department of Outcomes Research Consortium, Cleveland Clinic, Cleveland, $\mathrm{OH}$, USA.

Received: 16 February 2020 Accepted: 1 June 2020 Published online: 29 June 2020

\section{References}

1. Torre LA, Bray F, Siegel RL, Ferlay J, Lortet-Tieulent J, Jemal A. Global cancer statistics, 2012. CA Cancer J Clin. 2015;65(2):87-108. https://doi.org/10.3322/ caac. 21262.

2. Chen W, Zheng R, Baade PD, Zhang S, Zeng H, Bray F, et al. Cancer statistics in China, 2015. CA Cancer J Clin. 2016;66(2):115-32. https://doi.org/10.3322/ caac.21338.

3. Sullivan R, Alatise OI, Anderson BO, Audisio R, Autier P, Aggarwal A, et al. Global cancer surgery: delivering safe, affordable, and timely cancer surgery. Lancet Oncol. 2015;16(11):1193-224. https://doi.org/10.1016/s14702045(15)00223-5.

4. Detterbeck FC, Boffa DJ, Kim AW, Tanoue LT. The eighth edition lung Cancer stage classification. Chest. 2017;151(1):193-203. https://doi.org/10. 1016/j.chest.2016.10.010 
5. Ciechanowicz SJ, Ma D. Anaesthesia for oncological surgery - can it really influence cancer recurrence? Anaesthesia. 2016;71(2):127-31. https://doi.org/ 10.1111/anae.13342.

6. Kim R. Anesthetic technique and cancer recurrence in oncologic surgery: unraveling the puzzle. Cancer Metastasis Rev. 2017;36(1):159-77. https://doi. org/10.1007/s10555-016-9647-8

7. Byrne K, Levins KJ, Buggy DJ. Can anesthetic-analgesic technique during primary cancer surgery affect recurrence or metastasis? Can J Anaesth. 2016; 63(2):184-92. https://doi.org/10.1007/s12630-015-0523-8.

8. Salmasi V, Maheshwari K, Yang D, Mascha EJ, Singh A, Sessler DI, et al. Relationship between intraoperative hypotension, defined by either reduction from baseline or absolute thresholds, and acute kidney and myocardial injury after noncardiac surgery: a retrospective cohort analysis. Anesthesiology. 2017; 126(1):47-65. https://doi.org/10.1097/aln.0000000000001432.

9. Monk TG, Bronsert MR, Henderson WG, Mangione MP, Sum-Ping ST, Bentt $D R$, et al. Association between intraoperative hypotension and hypertension and 30-day postoperative mortality in noncardiac surgery. Anesthesiology. 2015;123(2):307-19. https://doi.org/10.1097/aln.0000000000000756.

10. Wesselink EM, Kappen TH, Torn HM, Slooter AJC, van Klei WA. Intraoperative hypotension and the risk of postoperative adverse outcomes: a systematic review. Br J Anaesth. 2018;121(4):706-21. https://doi.org/10.1016/j.bja.2018.04.036.

11. Bijker JB, van Klei WA, Vergouwe $Y$, Eleveld DJ, van Wolfswinkel $L$, Moons KG, et al. Intraoperative hypotension and 1-year mortality after noncardiac surgery. Anesthesiology. 2009;111(6):1217-26. https://doi.org/10.1097/ALN. Ob013e3181c14930.

12. Younes RN, Rogatko A, Brennan MF. The influence of intraoperative hypotension and perioperative blood transfusion on disease-free survival in patients with complete resection of colorectal liver metastases. Ann Surg. 1991;214(2):107-13. https://doi.org/10.1097/00000658-199108000-00003.

13. Park B, Jeong BC, Seo SI, Jeon SS, Choi HY, Lee HM. Influence of body mass index, smoking, and blood pressure on survival of patients with surgically-treated, low stage renal cell carcinoma: a 14-year retrospective cohort study. J Korean Med Sci. 2013;28(2):227-36. https://doi.org/10. 3346/jkms.2013.28.2.227.

14. Yu HC, Luo YX, Peng $H$, Wang $X L$, Yang $Z H$, Huang $M J$, et al. Association of perioperative blood pressure with long-term survival in rectal cancer patients. Chin J Cancer. 2016;35:38. https://doi.org/10.1186/ s40880-016-0100-8.

15. Huang WW, Zhu WZ, Mu DL, Ji XQ, Nie XL, Li XY, et al. Perioperative management may improve long-term survival in patients after lung Cancer surgery: a retrospective cohort study. Anesth Analg. 2018;126(5):1666-74. https://doi.org/10.1213/ane.0000000000002886

16. Goldstraw P, Crowley J, Chansky K, Giroux DJ, Groome PA, Rami-Porta R, et al. The IASLC lung Cancer staging project: proposals for the revision of the TNM stage groupings in the forthcoming (seventh) edition of the TNM classification of malignant tumours. J Thorac Oncol. 2007;2(8):706-14. https://doi.org/10.1097/JTO.0b013e31812f3c1a.

17. Bijker JB, van Klei WA, Kappen TH, van Wolfswinkel L, Moons KG, Kalkman CJ. Incidence of intraoperative hypotension as a function of the chosen definition: literature definitions applied to a retrospective cohort using automated data collection. Anesthesiology. 2007;107(2):213-20. https://doi. org/10.1097/01.anes.0000270724.40897.8e.

18. Strandberg TE, Pitkala K. What is the most important component of blood pressure: systolic, diastolic or pulse pressure? Curr Opin Nephrol Hypertens. 2003;12(3):293-7. https://doi.org/10.1097/01.mnh.0000069868.94246.ef.

19. Chobanian AV, Bakris GL, Black HR, Cushman WC, Green LA, Izzo JL Jr, et al. Seventh report of the Joint National Committee on Prevention, Detection, Evaluation, and Treatment of High Blood Pressure. Hypertension. 2003;42(6): 1206-52. https://doi.org/10.1161/01.HYP.0000107251.49515.c2.

20. Rami-Porta R, Bolejack V, Crowley J, Ball D, Kim J, Lyons G, et al. The IASLC lung Cancer staging project: proposals for the revisions of the T descriptors in the forthcoming eighth edition of the TNM classification for lung Cancer. J Thorac Oncol. 2015;10(7):990-1003. https://doi.org/10.1097/JTO. 0000000000000559 .

21. Sun Z, Aubry MC, Deschamps C, Marks RS, Okuno SH, Williams BA, et al. Histologic grade is an independent prognostic factor for survival in nonsmall cell lung cancer: an analysis of 5018 hospital- and 712 populationbased cases. J Thorac Cardiovasc Surg. 2006;131(5):1014-20. https://doi.org/ 10.1016/j.jtcvs.2005.12.057.

22. Zhong W, Yang X, Bai J, Yang J, Manegold C, Wu Y. Complete mediastinal lymphadenectomy: the core component of the multidisciplinary therapy in resectable non-small cell lung cancer. Eur J Cardiothorac Surg. 2008;34(1): 187-95. https://doi.org/10.1016/j.ejcts.2008.03.060.

23. Vansteenkiste J, Crino L, Dooms C, Douillard JY, Faivre-Finn C, Lim E, et al. 2nd ESMO consensus conference on lung Cancer: early-stage non-small-cell lung cancer consensus on diagnosis, treatment and follow-up. Ann Oncol. 2014:25(8):1462-74. https://doi.org/10.1093/annonc/mdu089.

24. Peduzzi $P$, Concato J, Feinstein AR, Holford TR. Importance of events per independent variable in proportional hazards regression analysis. II. Accuracy and precision of regression estimates. J Clin Epidemiol. 1995; 48(12):1503-10. https://doi.org/10.1016/0895-4356(95)00048-8.

25. Sessler DI, Bloomstone JA, Aronson S, Berry C, Gan TJ, Kellum JA, et al. Perioperative quality initiative consensus statement on intraoperative blood pressure, risk and outcomes for elective surgery. Br J Anaesth. 2019;122(5): 563-74. https://doi.org/10.1016/j.bja.2019.01.013.

26. Reich DL, Bennett-Guerrero E, Bodian CA, Hossain S, Winfree W, Krol M. Intraoperative tachycardia and hypertension are independently associated with adverse outcome in noncardiac surgery of long duration. Anesth Analg. 2002;95(2):273-7. https://doi.org/10.1097/00000539-200208000-00003.

27. Kheterpal S, O'Reilly M, Englesbe MJ, Rosenberg AL, Shanks AM, Zhang L, et al. Preoperative and intraoperative predictors of cardiac adverse events after general, vascular, and urological surgery. Anesthesiology. 2009;110(1): 58-66. https://doi.org/10.1097/ALN.0b013e318190b6dc.

28. Levin MA, Fischer GW, Lin HM, McCormick PJ, Krol M, Reich DL. Intraoperative arterial blood pressure lability is associated with improved 30 day survival. Br J Anaesth. 2015;115(5):716-26. https://doi.org/10.1093/bja/ aev293.

29. Futier E, Lefrant JY, Guinot PG, Godet T, Lorne E, Cuvillon P, et al. Effect of individualized vs standard blood pressure management strategies on postoperative organ dysfunction among high-risk patients undergoing major surgery: a randomized clinical trial. Jama. 2017;318(14):1346-57. https://doi.org/10.1001/jama.2017.14172.

30. Sessler DI, Sigl JC, Kelley SD, Chamoun NG, Manberg PJ, Saager L, et al. Hospital stay and mortality are increased in patients having a "triple low" of low blood pressure, low bispectral index, and low minimum alveolar concentration of volatile anesthesia. Anesthesiology. 2012;116(6):1195-203. https://doi.org/10.1097/ALN.0b013e31825683dc.

31. Walsh M, Devereaux PJ, Garg AX, Kurz A, Turan A, Rodseth RN, et al Relationship between intraoperative mean arterial pressure and clinical outcomes after noncardiac surgery: toward an empirical definition of hypotension. Anesthesiology. 2013;119(3):507-15. https://doi.org/10.1097/ ALN.0b013e3182a10e26.

32. Puelacher C, Lurati Buse G, Seeberger D, Sazgary L, Marbot S, Lampart A, et al. Perioperative myocardial injury after noncardiac surgery: incidence, mortality, and characterization. Circulation. 2018;137(12):1221-32. https://doi. org/10.1161/circulationaha.117.030114.

33. Sawhney S, Marks A, Fluck N, Levin A, Prescott G, Black C. Intermediate and long-term outcomes of survivors of acute kidney injury episodes: a large population-based cohort study. Am J Kidney Dis. 2017;69(1):18-28. https:// doi.org/10.1053/j.ajkd.2016.05.018.

34. Noman MZ, Messai Y, Carre T, Akalay I, Meron M, Janji B, et al. Microenvironmental hypoxia orchestrating the cell stroma cross talk, tumor progression and antitumor response. Crit Rev Immunol. 2011;31(5):357-77. https://doi.org/10.1615/critrevimmunol.v31.15.10.

35. Hiraga T, Kizaka-Kondoh S, Hirota K, Hiraoka M, Yoneda T. Hypoxia and hypoxia-inducible factor-1 expression enhance osteolytic bone metastases of breast cancer. Cancer Res. 2007;67(9):4157-63. https://doi.org/10.1158/ 0008-5472.can-06-2355.

36. Unwith $\mathrm{S}$, Zhao H, Hennah L, Ma D. The potential role of HIF on tumour progression and dissemination. Int J Cancer. 2015;136(11):2491-503. https:// doi.org/10.1002/ijc.28889.

37. Wanderer AA. Hypoxia and inflammation. N Engl J Med. 2011;364(20):1976; author reply 7. https://doi.org/10.1056/NEJMc1103019\#SA1.

38. Dolan RD, Lim J, McSorley ST, Horgan PG, McMillan DC. The role of the systemic inflammatory response in predicting outcomes in patients with operable cancer: systematic review and meta-analysis. Sci Rep. 2017;7(1): 16717. https://doi.org/10.1038/s41598-017-16955-5.

39. Lindholm LH, Anderson H, Ekbom T, Hansson L, Lanke J, Dahlof B, et al. Relation between drug treatment and cancer in hypertensives in the Swedish trial in old patients with hypertension 2: a 5-year, prospective, randomised, controlled trial. Lancet. 2001;358(9281):539-44. https://doi.org/ 10.1016/s0140-6736(01)05704-x.. 
40. Weberpals J, Jansen L, Haefeli WE, Hoffmeister M, Wolkewitz M, Herk-Sukel $\mathrm{M}$, et al. Pre- and post-diagnostic beta-blocker use and lung cancer survival: a population-based cohort study. Sci Rep. 2017;7(1):2911. https://doi.org/10. 1038/s41598-017-02913-8.

\section{Publisher's Note}

Springer Nature remains neutral with regard to jurisdictional claims in published maps and institutional affiliations.

Ready to submit your research? Choose BMC and benefit from:

- fast, convenient online submission

- thorough peer review by experienced researchers in your field

- rapid publication on acceptance

- support for research data, including large and complex data types

- gold Open Access which fosters wider collaboration and increased citations

- maximum visibility for your research: over $100 \mathrm{M}$ website views per year

At BMC, research is always in progress.

Learn more biomedcentral.com/submissions 